\title{
Kesehatan Bank Umum Syariah yang terdaftar di Otoritas Jasa Keuangan dengan metode Risk Based Bank Rating (RBBR)
}

\author{
Nardi Sunardi ${ }^{1)}$ \\ ${ }^{1)}$ dosen Universitas Pamulang, email : dosen01030@unpam.ac.id
}

\section{ARTICLES INFORMATION}

ABSTRACT

\section{JURNAL SEKURITAS \\ (Saham, Ekonomi, Keuangan dan Investasi ) \\ Vol.3, No.2, Januari 2020 Halaman : $132-147$ \\ (C) LPPM \& Prodi Manajemen UNVERSITAS PAMULANG \\ ISSN (online) : 2581-2777 ISSN (print) : : 2581-2696}

\section{Keyword : Bank Syariah \\ JEL. classification : Q15}

Metode Risk Based Bank Rating (RBBR) dan Tingkat Kesehatan

\section{Contact Author :}

PRODI MANAJEMEN UNPAM JL.Surya Kencana No.1

Pamulang Tangerang Selatan Banten

Telp. (021) 7412566, Fax (021) 7412491 Email :

sekuritas@unpam.ac.id

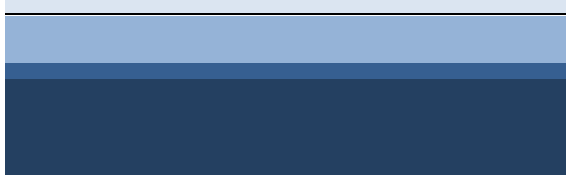

Penelitian ini bertujuan "untuk mengetahui kondisi profil risiko, rentabilitas, permodalan dan tingkat kesehatan Bank Umum Syariah (BUS) yang terdaftar di OJK dinilai dengan metode Risk Based Bank Rating (RBBR) selama periode 2014-2018. Jenis penelitian deskriptif dengan pendekatan kuantitatif digunakan dalam penelitian ini. Hasil penelitian menunjukkan bahwa faktor profil risiko BUS dengan faktor risk profile atas resiko kredit dengan rasio rata-rata secara keseluruhan NPF dengan predikat Sehat. Risiko Likuiditas menunjukkan bahwa rata-rata secara keseluruhan Financing to Deposit Ratio (FDR) dengan predikat Cukup Sehat, faktor earning (rentabilitas) dengan Return On Asset (ROA) predikat Sangat Sehat, dengan Net Interest Margin (NIM) predikat Sangat Sehat, sementara dilihat dari Beban \& Pendapatan Operasional (BOPO) dengan predikat Kurang Sehat. Analisis modal dengan Capital Adequency Ratio (CAR) predikat Sangat Sehat, Metode Risk Based Bank Rating (RBBR) menunjukkan nilai PK 2 dengan predikat Cukup Sehat berdasarkan Pasal 2 Peraturan bank Indonesia No. 13/1/PBI/2011 dan sesuai yang telah dijelaskan dalam SE BI No. 13/24/DPNP 25 Oktober 2011"

This study aims to "determine the condition of the risk profile, profitability, capital and health level of Sharia Commercial Banks (BUS) registered with OJK assessed by the Risk Based Bank Rating (RBBR) method during the 2014-2018 period. This type of descriptive research with a quantitative approach was used in this study. The results showed that the BUS risk profile factor with the risk profile factor for credit risk with an overall average ratio of NPF with the title of Healthy. Liquidity Risk shows that the overall average Financing to Deposit Ratio( FDR) with a predicate is quite Healthy, earnings factor (earnings) with a Return on Assets (ROA) predicate is Very Healthy, with a Net Interest Margin (NIM) the predicate is Very Healthy, while seen from Operating Expenses \& Income (BOPO) with the predicate to be Unhealthy. Capital analysis using the Capital Adequency Ratio (CAR) of the Very Healthy predicate, the Risk Based Bank Rating (RBBR) method shows a $P K$ value of 2 with a Fairly Healthy predicate based on Article 2 of Bank Indonesia Regulation No. 13/1 / PBI / 2011 and according to what has been explained in SE BI No. 13/24 / DPNP October 25, 2011". 


\section{A. PENDAHULUAN}

Majunya ekonomi Indonesia tidak lepas dari peran industri perbankan yang membantu kemajuan perekonomian tersebut. Secara umum bank memiliki peran yang sangat penting untuk perekonomian. Peran tersebut sebagai wahana yang mampu menghimpun dan menyalurkan dana secara efektif dan efisien kearah peningkatan hidup rakyat. Bank sebagai salah satu lembaga jasa keuangan sangat berperan penting dalam pembangunan dan kemajuan negara. Di negara berkembang seperti Indonesia, lembaga jasa keuangan bank masih memegang peran utama dalam menguasai aset keuangan. Laporan rencana utama di bidang Jasa Keuangan Indonesia tahun 2015-2019 yang dikeluarkan oleh Otoritas Jasa Keuangan RI menyebutkan bahwa lembaga jasa keuangan bank pada tahun 2014 menguasai sebanyak $74 \%$ dari total asset industri keuangan. Hal ini merupakan kondisi yang wajar mengingat lembaga jasa keuangan bank merupakan lembaga jasa keuangan yang paling banyak digunakan oleh masyarakat Indonesia untuk menyimpan maupun menginvestasikan dana yang dimiliki. Dana yang berhasil dihimpun oleh bank nantinya digunakan oleh bank untuk menyalurkan dana baik dalam bentuk pembiayan maupun pemberian kredit kepada masyarakat sehingga dapat membantu pertumbuhan ekonomi.

Dalam perkembangannya, berdasarkan prinsip transaksi, bank terbagi menjadi dua, yaitu Bank konvensional dan Bank Syariah. Bank Syariah merupakan bank yang menerapkan aturan perjanjian sesuai dengan hukum Islam antara bank dan pihak lainnya. Baik itu produk simpanan, pembiayaan usaha ataupun kegiatan lainnya. Bank syariah lahir sebagai salah satu solusi alternatif terhadap persoalan pertentangan antara bunga bank dan riba. Dengan demikian keinginan umat islam Indonesia yang terlepas dari persoalan riba telah terjawab dengan hadirnya perbankan syariah.

Dalam perkembangan selanjutnya dengan adana bank syariah di Indonesia cukup membangkan. Dengan dikeluarkannya "Undang-Undang Perbankan 1998 hasil revisi terhadap Undang-Undang Perbankan 1992, perbankan syariah memperoleh kesempatan untuk berkembang. Berdasarkan data OJK, hingga kini telah ada 14 Bank Umum Syariah (BUS) yang tercatat di Otoritas Jasa Keuangan Republik Indonesia. Berikut ini merupakan tabel yang menunjukan daftar nama bank umum syariah yang terdaftar di Otoritas Jasa Keuangan (OJK) pada tahun terakhir"

Tabel 1. Daftar Nama Bank Umum Syariah yang Terdaftar di OJK Tahun 2019

\begin{tabular}{|c|l|c|c|}
\hline No & \multicolumn{1}{|c|}{ Nama Bank } & $\begin{array}{c}\text { Tanggal } \\
\text { Pendirian }\end{array}$ & $\begin{array}{c}\text { Mulai } \\
\text { Beroperasi }\end{array}$ \\
\hline 1 & PT. Bank Aceh Syariah & $28-12-2001$ & $19-09-2016$ \\
\hline 2 & PT. BPD Nusa Tenggara Barat Syariah & $19-03-1999$ & $24-12-2018$ \\
\hline 3 & PT. Bank Muamalat Indonesia & $01-11-1991$ & $01-05-1992$ \\
\hline 4 & PT. Bank Victoria Syariah & $06-08-2009$ & $01-04-2010$ \\
\hline 5 & PT. Bank BRISyariah & $16-10-2008$ & $17-11-2008$ \\
\hline 6 & PT. Bank Jabar Banten Syariah & $15-01-2010$ & $06-05-2010$ \\
\hline 7 & PT. Bank BNI Syariah & $25-03-2010$ & $19-06-2010$ \\
\hline 8 & PT. Bank Syariah Mandiri & $25-10-1999$ & $01-11-1999$ \\
\hline 9 & PT. Bank Mega Syariah & $14-07-1990$ & $25-08-2004$ \\
\hline 10 & PT. Bank Panin Dubai Syariah & $06-10-2009$ & $02-12-2009$ \\
\hline 11 & PT. Bank Syariah Bukopin & $29-07-1990$ & $09-12-2008$ \\
\hline
\end{tabular}




\begin{tabular}{|c|l|c|c|}
\hline 12 & PT. BCA Syariah & $12-06-2009$ & $05-04-2010$ \\
\hline 13 & $\begin{array}{l}\text { PT.Bank Tabungan Pensiunan Nasional } \\
\text { Syariah }\end{array}$ & $27-08-2013$ & $14-07-2014$ \\
\hline 14 & PT. Maybank Syariah Indonesia & $30-04-2010$ & $11-10-2010$ \\
\hline
\end{tabular}

Tabel 1. menggambarkan seluruh nama bank syariah yang terdaftar di Otoritas Jasa Keuangan Indonesia pada tahun 2019. Peneliti memilih bank umum syariah yang terdaftar pada OJK untuk dijadikan sebagai sampel penelitian. Alasan peneliti memilih bank umum syariah karena perkembangan bank umum syariah belum berkembang secara pesat di Indonesia, padahal jika dilihat dari sisi agama, banyak sekali kebaikankebaikan serta keunggulan bank syariah dibandingkan bank konvensional. Dan mengapa bank konvensional melirik dan bahkan mengkonversi untuk membuka bank syariah adalah karena mayoritas penduduk di Indonesia menganut agama islam yang mana mereka telah menyadari adanya keharamanan pada bunga bank konvensional yang telah dikeluarkan fatwanya oleh MUI. "Bank syariah menganut sistem bagi hasil yang diyakini lebih menguntungkan dibandingkan bunga dari bank konvensional. Bank syariah tidak membenarkan adanya bunga bank, karena bunga bank termasuk dalam riba, dan riba itu haram hukumnya selain itu dari segi keunggulan lain bank syariah memiliki produkproduk perbankan tidak ada yang bersifat spekulatif sehingga tidak akan terpengaruh oleh krisis ekonomi global. Bank Syariah dalam pembiayaan lebih memilih sektor riil sehingga memberikan pengaruh yang lebih besar terhadap pertumbuhan ekonomi, hal ini yang menjadi daya tarik para investor untuk berinvestasi pada perusahaan sektor perbankan syariah di Indonesia".

Namun pada tahun 2019, Otoritas Jasa Keuangan (OJK) "mencatat pertumbuhan industri keuangan syariah nasional hingga Mei 2019 sebesar 11,25\%, melambat dibanding posisi akhir 2018 sebesar 13,98\%. Regulator keuangan itu merinci nilai pasar modal syariah hingga periode yang sama mencapai Rp 727,08 triliun, INKB sebesar Rp 100,49 triliun, dan total aset perbankan sebesar Rp 484,62 triliun. Adapun pangsa pasar perbankan syariah saat ini masih mencapai 5,85\% dari total industri perbankan".

Menurunnya perkembangan Bank Syariah disebabkan beberapa faktor. Seperti diungkapkan oleh Direktur Perbankan Syariah OJK Dhani Gunawan Idhat "penyebab pertama adalah belum selarasnya visi serta kurangnya koordinasi antara pemerintah dengan otoritas dalam perkembangan perbankan syariah, Persoalan kedua adalah masih banyak bank syariah yang memiliki modal belum memadai. Kurangnya modal akan menghambat bank-bank syariah dalam membuka kantor cabang, mengembangkan infrastruktur, dan pengembangan segmen layanan. Persoalan lainnya ialah Produk BUS yang kurang variatif dan pelayanan yang belum sesuai ekspektasi masyarakat. Fitur bank syariah belum selengkap produk serupa bank konvensional. Di Malaysia, ada 45 ragam produk perbankan syariah, di Indonesia hanya sekitar 15". Dari beberapa persoalan tersebut diperlukan pengawasan untuk memantau dan memeriksa pengelolaan yang sesuai dengan ketentuan perbankan.

Pengawasan terhadap bank juga dilakukan untuk mengetahui dalam mengukur tingkat kesehatan. Kesehatan bank dinilai sebagai kemampuan suatu bank dalam melakukan kegiatan operasional perbankan secara normal dan mampu memenuhi semua kewajibannya dengan baik, sesuai dengan peraturan yang berlaku. Bank Indonesia menerbitkan Peraturan Bank Indonesia No. 13/1/PBI/2011 mengenai tingkat kesehatan bank yang dinilai dengan metode RBBR (Risk Based Bank Rating). RBBR terdiri dari empat faktor yakni, profil risiko (risk profie), good corporate governance (GCG), rentabilitas (earning), permodalan (capital). Faktor risk profile "dilakukan penilaian terhadap risiko dan penerapan manajemen risiko dalam kegiatan operasional bank terhadap delapan risiko yakni, risiko kredit, risiko pasar, risiko likuiditas, risiko 
operasional, risiko hukum, risiko stratejik, risiko kepatuhan, dan risiko reputasi. Faktor GCG dilakukan penilaian terhadap kualitas manajemen bank berdasarkan prinsip-prinsip GCG. Faktor earning merupakan penilaian yang meliputi kinerja, sumber, kesinambungan, dan manajemen rentabilitas, rasio yang menunjukkan kinerja rentabilitas yakni Return On Asset (ROA) dan Net Interest Margin (NIM)". Berdasarkan SE BI No. 13/24/DPNP menjelaskan bahwa "penilaian atas faktor permodalan meliputi evaluasi terhadap kecukupan permodalan dan kecukupan pengelolaan permodalan", "permodalan bank dapat diukur dengan rasio Capital Adequency Ratio (CAR").

Bank Umum Syariah (BUS) di Indonesia sangat perlu menjaga tingkat kesehatan. Faktor lain selain kendala BUS yang telah disebutkan sebelumnya, yang rentan dihadapi seluruh perbankan adalah risiko kredit. "Risiko kredit dalam sistem perbankan berarti bahwa pembayaran kredit tertunda atau tidak ada sama sekali yang dapat menyebabkan masalah arus kas dan mempengaruhi likuiditas bank, oleh karena itu risiko kredit merupakan penyebab utama kegagalan bank". Berdasarkan latar belakang masalah yang dipaparkan, maka peneliti tertarik mengajukan penelitian dengan judul "Analisis Tingkat Kesehatan Bank Dengan Menggunakan Metode Risk Based Bank Rating (RBBR) Pada Bank Umum Syariah Yang Terdaftar Di Otoritas Jasa Keuangan Periode 2014-2018".

\section{B. KAJIAN LITERATUR}

\section{BANK}

Pengertian Bank adalah "lembaga intermediasi keuangan yang bertugas menghimpun dan menyalurkan dana di masyarakat untuk meningkatkan taraf hidup rakyat. Sedangkan pengertian perbankan adalah segala sesuatu yang berhubungan tentang bank. Penghimpunan dana dari masyarakat dilakukan bank melalui simpanan atau tabungan dan penyaluran dana dilakukan melalui kredit atau pinjaman kepada masyarakat. Selain dari kedua tugas itu, menurut Undang-undang Negara Republik Indonesia Nomor 10 Tahun 1998, bank juga memberikan jasa bank lainnya. Seiring dengan perkembangan zaman, industri perbankan mengalami perubahan besar karena deregulasi peraturan. Sehingga mengakibatkan bank lebih kompetitif dalam menyediakan jasa bank lainnya. Jasa tersebut di antaranya termasuk transfer dana antar rekening, pembayaran tagihan, sarana investasi, penukaran mata uang asing dan banyak lagi".

\section{BANK SYARIAH}

Pengertian Bank Syariah menurut UU No. 21 tahun 2008 tentang Perbankan Syariah, "Bank Syariah adalah bank yang menjalankan kegiatan usaha berdasarkan prinsip syariah, atau prinsip hukum islam yang diatur dalam fatwa Majelis Ulama Indonesia seperti prinsip keadilan dan keseimbangan ('adl wa tawazun), kemaslahatan (maslahah), universalisme (alamiyah), serta tidak mengandung gharar, maysir, riba, zalim dan obyek yang haram. Selain itu, UU Perbankan Syariah juga mengamanahkan bank syariah untuk menjalankan fungsi sosial dengan menjalankan fungsi seperti lembaga baitul mal, yaitu menerima dana yang berasal dari zakat, infak, sedekah, hibah, atau dana sosial lainnya dan menyalurkannya kepada pengelola wakaf (nazhir) sesuai kehendak pemberi wakaf (wakif)".

\section{LAPORAN KEUANGAN}

Pengertian laporan keuangan berdasarkan Ikatan Akuntan Indonesia adalah "bagian dari proses laporan keuangan yang lengkap yang meliputi neraca, laporan laba rugi, laporan perubahan posisi keuangan, catatan dan laporan lain, serta merupakan bagian integral dari laporan keuangan (IAI, 2009:2). Berdasarkan Ikatan Akuntan Indonesia (2009:3), laporan keuangan bertujuan untuk menyediakan informasi yang menyangkut posisi keuangan, kinerja, serta pembahasan posisi keuangan suatu perusahaan yang bermanfaat bagi sejumlah besar pemakai dalam pengambilan keputusan ekonomi. 
Unsur-unsur laporan keuangan berdasarkan Standar Akuntansi Keuangan (SAK, 2009:12) yaitu neraca, laporan laba rugi, laporan perubahan ekuitas, laporan arus kas, dan catatan atas laporan keuangan".

\section{KESEHATAN BANK}

Kesehatan bagi lembaga perbankan juga merupakan aspek yang penting. "Kesehatan bank adalah sarana bagi otoritas pengawas dengan memberikan pengawasan pada bank. Secara sederhana, Bank yang sehat merupakan bank yang dapat menjalankan fungsi-fungsi bank dengan baik. Perbankan harus dinilai kesehatannya agar tetap prima dalam melayani nasabahnya. Penilaian kesehatan bank dilakukan setiap tahun untuk melihat adanya peningkatan atau penurunan kesehatan. Kesehatan bank merupakan kepentingan semua pihak yang terkait yakni, pemilik, manajemen, masyarakat (nasabah pengguna jasa), dan Bank Indonesia selaku pengawas dan pembinan perbankan". Sistem penilaian dalam menetapkan tingkat kesehatan bank didasarkan pada pemberian "reward system" adalah dengan memberikan penilaian menggunakan ukuran (1-100) dalam pemeringkatan baik dengan skala kredit maupun dengan skala nilai rasio dan digolongkan dalan 5 peringkat atau disingkat (PK):

Tabel 2. Peringkat Komposit

\begin{tabular}{|c|l|}
\hline Peringkat & \multicolumn{3}{|c|}{ Komposit Keterangan } \\
\hline 1 & $\begin{array}{l}\text { "Mencerminkan bahwa bank tergolong sangat sehat dan mampu } \\
\text { mengatasi pengaruh negatif kondisi perekonomian dan industri } \\
\text { keuangan". }\end{array}$ \\
\hline 2 & $\begin{array}{l}\text { "Mencerminkan bahwa bank tergolong sehat dan mampu mengatasi } \\
\text { pengaruh negatif namun bank masih memiliki kelemahan-kelemahan } \\
\text { yang dapat segera diatasi oleh tindakan rutin". }\end{array}$ \\
\hline 3 & $\begin{array}{l}\text { "Mencerminkan bahwa bank tergolong cukup sehat namun terdapat } \\
\text { kelemahan yang dapat menyebabkan peringkat kompositnya memburuk } \\
\text { apabila bank tidak segera melakukan tindakan korektif". }\end{array}$ \\
\hline 4 & $\begin{array}{l}\text { "Mencerminkan bahwa bank tergolong kurang sehat dan sensitif } \\
\text { terhadap negatif kondisi perekonomian dan industri keuangan atau bank } \\
\text { memiliki kelemahan keuangan yang serius atau kombinasi dari kondisi } \\
\text { beberapa faktor yang tidak memuaskan, yang apabila tidak dilakukan } \\
\text { tindakan korektif yang efektif berpotensi mengalami kesulitan yang } \\
\text { membahayakan kelangsungan usahanya". }\end{array}$ \\
\hline 5 & $\begin{array}{l}\text { "Mencerminkan bahwa bank tergolong tidak sehat dan sangat sensitive } \\
\text { terhadap pengaruh negatif kondisi perekonomian dan industri keuangan } \\
\text { serta mengalami kesulitan yang membahayakan kelangsungan } \\
\text { usahanya". }\end{array}$ \\
\hline
\end{tabular}

Sumber: Peraturan Bank Indonesia No. 6/10/PBI tanggal 12 April 2004

Tingkat kesehatan bank dibagi dalam lima kategori yaitu: "sangat sehat, sehat, cukup sehat, kurang sehat dan tidak sehat". Dalam penerapan ketentuan tersebut memerlukan persyaratan tingkat kesehatan bank maka predikat ukuran Kesehatan Bank disesuaikan dengan ketentuan dalam "Surat Edaran Bank Indonesia No. 6/23/DPNP tanggal 31 Mei 2004" sebagai berikut:

a. Tingkat Kesehatan "Sehat" dinilai menggunakan peringkat komposit $1(\mathrm{PK}-1)$ atau peringkat komposit 2 (PK-2).

b. Tingkat Kesehatan "Cukup Sehat" dinilai menggunakan peringkat komposit 3 (PK-3).

c. Tingkat Kesehatan "Kurang Sehat" dinilai menggunakan peringkat komposit 4 (PK4).

d. Tingkat Kesehatan "Tidak Sehat" dinilai menggunakan peringkat komposit 5 (PK-5). 


\section{METODE RISK BASED BANK RATING (RBBR)}

Bank Indonesia pada tanggal 5 Januari 2011 mengeluarkan peraturan mengenai Tingkat Kesehatan Bank melalui Peraturan Bank Indonesia No. 13/1/PBI/2011 yaitu "penilaian tingkat kesehatan bank dengan menggunakan pendekatan berdasarkan risiko atau RBBR (Risk-Based Bank Rating). Metode ini terdiri dari empat faktor penialaian, antara lain: Risk Profile (Profil Risiko), Good Corporate Governance (GCG), Earning (Rentabilitas), Capital (Permodalan). Namun, penilaian faktor Good Corporate Governance (GCG) tidak dapat dianalisa karena membutuhkan data primer yang menyangkut kerahasiaan bank. Berikut ini penjelasan mengenai tiga faktor penilaian":

\section{Profil Risiko (Risk Profile)}

Berdasarkan PBI No. 13/1/PBI/2011 "bank melakukan penilaian terhadap risiko inheren dan kualitas penerapan manajemen risiko dalam kegiatan operasional terhadap delapan risiko, yakni risiko kredit, risiko pasar, risiko likuiditas, risiko operasional, risiko hukum, risiko stratejik, risiko kepatuhan, dan risiko reputasi. Penelitian ini mengukur tiga risiko pada faktor risk profile menggunakan rasio Non Performing Financing (NPF) untuk mengukur risiko kredit, rasio Interest Rate Risk (IRR) untuk mengukur risiko pasar, dan rasio Financing to Deposit Ratio (FDR) untuk mengukur risiko likuiditas".

a. Rumusan Risiko kredit dapat dihitung menggunakan sebagai berikut :

$$
\text { Non Performing Financing }(N P F)=\frac{\text { Kredit Bermasalah }}{\text { Total kredit }} \times 100 \%
$$

Sumber: Lampiran SE BI 13/24/DPNP/2011

Tabel 3 Predikat Non Performing Financing Bank

\begin{tabular}{|c|c|c|}
\hline No. & Rasio & Predikat \\
\hline 1 & "0\% $<$ NPF $<2 \% "$ & "Sangat Sehat" \\
\hline 2 & "2\% $\leq \mathrm{NPF}<5 \% "$ & "Sehat" \\
\hline 3 & "5\% $\leq \mathrm{NPF}<8 \% "$ & "Cukup Sehat" \\
\hline 4 & "K\% $<\mathrm{NPF} \leq 11 \% "$ & "Tidan Sehat" \\
\hline 5 & "NPF $>11 \% "$ & \\
\hline
\end{tabular}

b. Rumusan Risiko Likuiditas dihitung menggunakan Financing to Deposit Ratio (FDR) sebagai berikut :

Tabel 4 Predikat Financing to Deposito Ratio Bank

\begin{tabular}{|c|c|c|c|}
\hline \multirow{2}{*}{\multicolumn{2}{|c|}{ Financing to Deposit Ratio $(F D R)=$}} & Total Kredit & \multirow{2}{*}{ x $100 \%$} \\
\hline & & Dana Pihak Ketiga & \\
\hline \multicolumn{4}{|c|}{ Sumber: Lampiran SE BI 13/24/DPNP/2011 } \\
\hline No. & Rasio & Predikat & \\
\hline 1 & "50\% < FDR $\leq 75 \% "$ & "Sangat Sehat" & \\
\hline
\end{tabular}




\begin{tabular}{|c|c|c|}
\hline 2 & "75\% < FDR $\leq 85 \% "$ & "Sehat" \\
\hline 3 & "85\% < FDR $\leq 100 \% "$ & "Cukup Sehat" \\
\hline 4 & "100\% < FDR $\leq 120 \% "$ & "Kurang Sehat" \\
\hline 5 & "FDR $>120 \% "$ & "Tidak Sehat" \\
\hline
\end{tabular}

Sumber: Lampiran SE BI 13/24/DPNP/2011

\section{Rentabilitas (Earnings)}

Rumusan dalam penilaian earning bank milik pemerintah pusat menggunakan parameter diantaranya adalah:

a. Return On Asset (ROA)

$$
\text { Return On Asset (ROA) }=\frac{\text { Laba Sebelum Pajak }}{\text { Rata-Rata Total Aset }} \times 100 \%
$$

Sumber: Lampiran SE BI 13/24/DPNP/2011

Tabel 5 Predikat Bank berdasarkan ROA

\begin{tabular}{|c|c|c|}
\hline No. & Rasio & Predikat \\
\hline 1 & " $\%<$ ROA" & "Sangat Sehat" \\
\hline 2 & " $1,25 \%<\mathrm{ROA} \leq 2 \% "$ & "Sehat" \\
\hline 3 & "0,5\%<ROA $\leq 1,25 \% "$ & "Cukup Sehat" \\
\hline 4 & "0\%<ROA $\leq 0,5 \% "$ & "Kurang Sehat" \\
\hline 5 & "ROA $\leq 0 \% "$ & "Tidak Sehat" \\
\hline
\end{tabular}

Sumber: Lampiran SE BI 13/24/DPNP/2011

\section{b. Net Interest Margin (NIM)}

$$
\text { Net Interest Margin (NIM) }=\frac{\text { Pendapatan Bunga Bersih }}{\text { Rata-Rata Total Earning Aset }} \times 100 \%
$$

Sumber: Lampiran SE BI 13/24/DPNP/2011

Tabel 6 Predikat Kesehatan berdasarkan NIM

\begin{tabular}{|c|c|c|}
\hline No. & Rasio & Predikat \\
\hline 1 & "3\%< NIM" & "Sangat Sehat" \\
\hline 2 & "2\% < NIM $\leq 3 \% "$ & "Sehat" \\
\hline 3 & " $1,5 \%<\mathrm{NIM} \leq 2 \% "$ & "Cukup Sehat" \\
\hline 4 & "Kurang Sehat" \\
\hline 5 & "NIM $\leq 1,5 \% "$ & "Tidak Sehat" \\
\hline
\end{tabular}

Sumber: "Lampiran SE BI 13/24/DPNP/2011" 


\section{c. Beban Operasional Pendapatan Operasional (BOPO)}

"BOPO merupakan perbandingan antara beban operasional terhadap pendapatan operasional. Rasio ini digunakan untuk mengukur tingkat efisiensi dan kemampuan bank dalam melakukan kegiatan operasionalnya" (Kaligis, 2013). Rasio BOPO dapat dihitung menggunakan rumus sebagai berikut:

$$
B O P O=\frac{\text { Biaya Operasional }}{\text { Pendapatan Operasional }} \times 100 \%
$$

Sumber: Lampiran SE BI 13/24/DPNP/2011

Tabel 7 Predikat Kesehatan berdasarkan BOPO

\begin{tabular}{|c|c|c|}
\hline No. & Rasio & Predikat \\
\hline 1 & "BOPO $\leq 94 \% "$ & "Sangat Sehat" \\
\hline 2 & "94\% < BOPO $\leq 95 \% "$ & "Sehat" \\
\hline 3 & "95\%< BOPO $\leq 96 \% "$ & "Cukup Sehat" \\
\hline 4 & " $96 \%<$ BOPO $\leq 97 \% "$ & "Tidak Sehat" \\
\hline 5 & "BOPO $>97 \% "$ & "Tidang Sehat" \\
\hline
\end{tabular}

Sumber: Lampiran SE BI 13/24/DPNP/2011

\section{Permodalan (Capital)}

"Rasio Capital Adequency Ratio (CAR) dapat digunakan untuk mengukur kecukupan modal yang dimiliki bank dan pemenuhan Kewajiban Penyediaan Modal Minimum (KPMM). Rumus CAR yang digunakan" adalah :

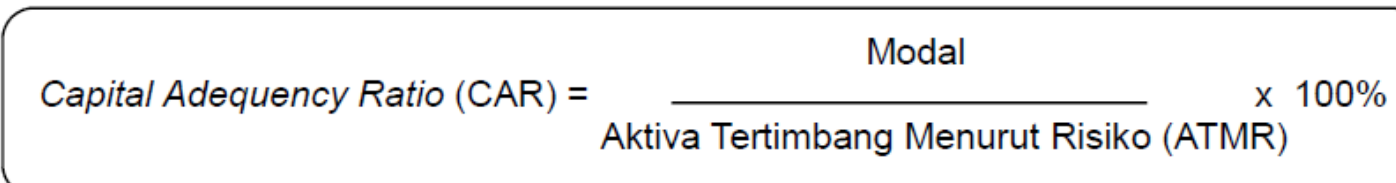

Sumber: Lampiran SE BI 13/24/DPNP/2011

Tabel 8 Predikat Kesehatan berdasarkan BOPO

\begin{tabular}{|c|c|c|}
\hline No. & Rasio & Predikat \\
\hline 1 & " $12 \%<$ CAR" & "Sangat Sehat" \\
\hline 2 & "9\%<CAR $\leq 12 \% "$ & "Sehat" \\
\hline 3 & " $\%<<$ CAR $\leq 9 \% "$ & "Cukup Sehat" \\
\hline 4 & "6\% $<$ CAR $\leq 8 \% "$ & "Tidak Sehat" \\
\hline 5 & "CAR $\leq 6 \% "$ & "Cehat" \\
\hline
\end{tabular}

Sumber: Lampiran SE BI 13/24/DPNP/2011 


\section{METODOLOGI PENELITIAN}

Metode penelitian deskriptif dengan pendekatan kuantitatif merupakan pendekatan penelitian ini. Data sekunder adalah jenis data yang digunakan dalam penelitian ini, yaitu data yang telah dikumpulkan oleh lembaga pengumpul data dan dipublikasikan kepada masyarakat pengguna data.

Metode pengumpulan data dengan dokumentasi dalam penelitian ini merupakan pengumpulan data dengan cara pengambilan dari data sekunder yang sudah didokumentasikan yang berupa laporan keuangan tahunan yang diperoleh dari website www.idx.co.id masing-masing bank untuk mendapatkan data laporan keuangan berupa neraca dan laporan rugi laba.

\section{HASIL DAN PEMBAHASAN}

Penelitian ini melakukan analisis tingkat kesehatan bank dengan menggunakan metode risk based bank rating (RBBR) dalam penelitian ini ditunjukkan dalam hasil dibawah ini:

\section{Analisis Profil Risiko (Risk Profile)}

Penelitian ini mengukur risiko kredit pada faktor risk profile menggunakan rasio Non Performing Financing (NPF) dan rasio Financing to Deposit Ratio (FDR) untuk mengukur risiko likuiditas.

\section{a. Risiko Kredit}

Berdasarkan Tabel 9 menunjukkan "bahwa rata-rata secara keseluruhan NPF Bank Umum Syariah (BUS) yaitu 3.17\% dengan predikat Sehat. NPF tertinggi dimiliki oleh Bank Syariah Mandiri dengan nilai rata-rata NPF sebesar $5.13 \%$ dengan predikat Cukup Sehat karena meningkatnya jumlah kredit bermasalah Bank Syariah Mandiri. NPF terendah dimiliki oleh Bank BCA Syariah dengan nilai NPF sebesar $0.39 \%$ dengan predikat Sangat Sehat karena rendahnya kredit bermasalah yang dimiliki Bank BCA Syariah"

\section{Tabel 9 Kesehatan Bank Berdasarkan Rasio NPF}

\begin{tabular}{|c|c|c|c|c|c|c|c|c|c|}
\hline \multirow[t]{2}{*}{ No. } & \multirow{2}{*}{$\begin{array}{c}\text { Nama Bank Umum Syariah } \\
\text { Indonesia }\end{array}$} & \multicolumn{5}{|c|}{$\begin{array}{c}\text { Non Performing Loan } \\
\text { (NPL/NPF) }\end{array}$} & \multirow{2}{*}{$\begin{array}{l}\text { Rata- } \\
\text { Rata }\end{array}$} & \multirow[t]{2}{*}{ Predikat } & \multirow{2}{*}{$\begin{array}{l}\text { Pering } \\
\text { kat }\end{array}$} \\
\hline & & 2014 & 2015 & 2016 & 2017 & 2018 & & & \\
\hline 1 & PT Bank Muamalat Indonesia & 6.01 & 7.46 & 3.97 & 3.90 & 2.63 & 4.79 & "Sehat" & 4 \\
\hline 2 & PT Bank Syariah Mandiri & 6.84 & 6.06 & 4.92 & 4.53 & 3.28 & 5.13 & $\begin{array}{l}\text { "Cukup } \\
\text { Sehat" }\end{array}$ & 3 \\
\hline 3 & PT Bank BTPN Syariah & 1.29 & 1.26 & 1.53 & 1.67 & 1.39 & 1.43 & $\begin{array}{l}\text { "Sangat } \\
\text { Sehat" }\end{array}$ & 1 \\
\hline 4 & PT Bank BRI Syariah & 3.65 & 3.89 & 3.19 & 4.75 & 4.97 & 4.09 & "Sehat" & 4 \\
\hline \multirow[t]{2}{*}{5} & PT Bank BCA Syariah & 0.10 & 0.70 & 0.50 & 0.32 & 0.35 & 0.39 & $\begin{array}{l}\text { "Sangat } \\
\text { Sehat" }\end{array}$ & 1 \\
\hline & RATA-RATA & 3.58 & 3.87 & 2.82 & 3.03 & 2.52 & 3.17 & "Sehat" & 4 \\
\hline
\end{tabular}

Sumber: Data diolah (2019)

\section{b. Risiko Likuiditas}

Berdasarkan Tabel 10 "menunjukkan bahwa rata-rata secara keseluruhan Financing to Deposit Ratio (FDR/LDR) Bank Umum Syariah (BUS) yaitu $86.14 \%$ dengan predikat Cukup Sehat. FDR tertinggi dimiliki oleh Bank BTPN Syariah dengan nilai rata-rata FDR sebesar 94.28\% dengan predikat Cukup Sehat Hal tersebut menunjukkan bahwa 
semakin rendahnya likuiditas Bank BTPN Syariah karena jumlah dana dari masayarakat yang disalurkan ke kredit terlalu besar. FDR terendah dimiliki oleh Bank Syariah Mandiri dengan nilai FDR sebesar $79.60 \%$ dengan predikat Sehat karena rendahnya kredit yang dimiliki Bank Syariah Mandir"i.

Tabel 10 Kesehatan Bank Berdasarkan Rasio FDR

\begin{tabular}{|c|c|c|c|c|c|c|c|c|c|}
\hline \multirow[t]{2}{*}{ No. } & \multirow{2}{*}{$\begin{array}{c}\text { Nama Bank Umum Syariah } \\
\text { Indonesia }\end{array}$} & \multicolumn{5}{|c|}{$\begin{array}{c}\text { Loan to Deposit Ratio } \\
\text { (LDR/FDR) }\end{array}$} & \multirow{2}{*}{$\begin{array}{l}\text { Rata- } \\
\text { Rata }\end{array}$} & \multirow[t]{2}{*}{ Predikat } & \multirow{2}{*}{$\begin{array}{l}\text { Pering } \\
\text { kat }\end{array}$} \\
\hline & & 2014 & 2015 & 2016 & 2017 & 2018 & & & \\
\hline 1 & PT Bank Muamalat Indonesia & 84.14 & 90.30 & 95.13 & 84.41 & 73.18 & 85.43 & $\begin{array}{l}\text { "Cukup } \\
\text { Sehat" }\end{array}$ & 3 \\
\hline 2 & PT Bank Syariah Mandiri & 81.92 & 81.99 & 79.19 & 77.66 & 77.25 & 79.60 & "Sehat" & 4 \\
\hline 3 & PT Bank BTPN Syariah & 94.00 & 96.60 & 92.70 & 92.50 & 95.60 & 94.28 & $\begin{array}{l}\text { "Cukup } \\
\text { Sehat" }\end{array}$ & 3 \\
\hline 4 & PT Bank BRI Syariah & 93.90 & 84.16 & 81.42 & 71.87 & 775.49 & 81.37 & "Sehat" & 4 \\
\hline \multirow[t]{2}{*}{5} & PT Bank BCA Syariah & 91.20 & 91.40 & 90.10 & 88.50 & 89.00 & 90.04 & $\begin{array}{l}\text { "Cukup } \\
\text { Sehat" }\end{array}$ & 3 \\
\hline & RATA-RATA & 89.03 & 88.89 & 87.71 & 82.99 & 82.10 & 86.14 & $\begin{array}{l}\text { "Cukup } \\
\text { Sehat" }\end{array}$ & 3 \\
\hline
\end{tabular}

Sumber: Data diolah (2019)

\section{Analisis Earnings (Rentabilitas)}

Penelitian ini mengukur Analisis Earnings (Rentabilitas) pada faktor earnings menggunakan Return On Asset (ROA), Net Interest Margin (NIM) dan Beban sertA Pendapatan Operasional (BOPO) sebagai berikut :

\section{a. Return On Asset (ROA)}

Berdasarkan Tabel 11 "menunjukkan bahwa rata-rata secara keseluruhan Return On Asset (ROA) Bank Umum Syariah (BUS) yaitu 2.14\% dengan predikat Sangat Sehat dengan nilai PK 1. ROA tertinggi dimiliki oleh Bank BTPN Syariah dengan nilai ratarata $\mathrm{ROA}$ sebesar $8.40 \%$ dengan predikat Sangat Sehat dengan nilai PK 1, karena meningkatnya pendapatan atas aset di Bank BTPN Syariah. ROA terendah dimiliki oleh Bank Muamalat Indonesia dengan nilai ROA sebesar $0.16 \%$ dengan predikat Kurang Sehat karena pendapatan atas aset di Bank Muamalat Indonesia".

Tabel 11 Kesehatan Bank Berdasarkan Rasio ROA

\begin{tabular}{|c|c|c|c|c|c|c|c|c|c|}
\hline \multirow{2}{*}{ No. } & \multirow{2}{*}{$\begin{array}{c}\text { Nama Bank Umum Syariah } \\
\text { Indonesia }\end{array}$} & \multicolumn{5}{|c|}{ Return On Asset (ROA) } & \multirow{2}{*}{$\begin{array}{l}\text { Rata- } \\
\text { Rata }\end{array}$} & \multirow{2}{*}{ Predikat } & \multirow{2}{*}{$\begin{array}{l}\text { Perin } \\
\text { gkat }\end{array}$} \\
\hline & & 2014 & 2015 & 2016 & 2017 & 2018 & & & \\
\hline 1 & PT Bank Muamalat Indonesia & 0.17 & 0.20 & 0.22 & 0.11 & 0.08 & 0.16 & $\begin{array}{l}\text { "Kurang } \\
\text { Sehat" }\end{array}$ & 4 \\
\hline 2 & PT Bank Syariah Mandiri & -0.04 & 0.56 & 0.59 & 0.59 & 0.88 & 0.52 & $\begin{array}{l}\text { "Cukup } \\
\text { Sehat" }\end{array}$ & 3 \\
\hline 3 & PT Bank BTPN Syariah & 4.20 & 5.20 & 9.00 & 11.20 & 12.40 & 8.40 & $\begin{array}{l}\text { "Sangat } \\
\text { Sehat" }\end{array}$ & 1 \\
\hline 4 & PT Bank BRI Syariah & 0.08 & 0.77 & 0.95 & 0.51 & 0.43 & 0.55 & $\begin{array}{l}\text { "Cukup } \\
\text { Sehat" }\end{array}$ & 3 \\
\hline 5 & PT Bank BCA Syariah & 0.80 & 1.00 & 1.10 & 1.20 & 1.20 & 1.06 & $\begin{array}{l}\text { "Cukup } \\
\text { Sehat" }\end{array}$ & 3 \\
\hline & RATA-RATA & 1.04 & 1.55 & 2.37 & 2.72 & 3.00 & 2.14 & $\begin{array}{l}\text { "Sangat } \\
\text { Sehat" }\end{array}$ & 1 \\
\hline
\end{tabular}

Sumber: Data diolah (2019) 


\section{b. Net Interest Margin (NIM)}

Berdasarkan Tabel 12 "menunjukkan bahwa rata-rata secara keseluruhan Net Interest Margin (NIM) Bank Umum Syariah (BUS) yaitu 10.30\% dengan predikat Sangat Sehat dengan nilai PK 1. NIM tertinggi dimiliki oleh Bank BTPN Syariah dengan nilai rata-rata ROA sebesar $29.89 \%$ dengan predikat Sangat Sehat dengan nilai PK 1, karena meningkatnya jumlah pendapatan bunga bersih Bank BTPN Syariah. NIM terendah dimiliki oleh Bank Muamalat Indonesia dengan nilai NIM sebesar 3.07\% dengan predikat Sangat Sehat karena rendahnya pendapatan bunga bersih Bank Muamalat Indonesia".

Tabel 12 Kesehatan Bank Berdasarkan Rasio NIM

\begin{tabular}{|c|c|c|c|c|c|c|c|c|c|}
\hline No. & $\begin{array}{c}\text { Nama Bank Umum Syariah } \\
\text { Indonesia }\end{array}$ & \multicolumn{5}{|c|}{ Net Interest Margin (NIM) } & $\begin{array}{l}\text { Rata- } \\
\text { Rata }\end{array}$ & Predikat & $\begin{array}{l}\text { Perin } \\
\text { gkat }\end{array}$ \\
\hline 1 & PT Bank Muamalat Indonesia & 3.36 & 4.09 & 3.21 & 2.48 & 2.22 & 3.07 & $\begin{array}{l}\text { "Sangat } \\
\text { Sehat" }\end{array}$ & 1 \\
\hline 2 & PT Bank Syariah Mandiri & 6.22 & 6.54 & 6.75 & 7.35 & 6.56 & 6.68 & $\begin{array}{l}\text { "Sangat } \\
\text { Sehat" }\end{array}$ & 1 \\
\hline 3 & PT Bank BTPN Syariah & 10.96 & 34.31 & 35.78 & 35.96 & 32.42 & 29.89 & $\begin{array}{l}\text { "Sangat } \\
\text { Sehat" }\end{array}$ & 1 \\
\hline 4 & PT Bank BRI Syariah & 6.04 & 6.38 & 6.37 & 5.84 & 5.36 & 6.00 & $\begin{array}{l}\text { "Sangat } \\
\text { Sehat" }\end{array}$ & 1 \\
\hline 5 & PT Bank BCA Syariah & 4.20 & 4.90 & 4.80 & 4.30 & 4.40 & 4.52 & $\begin{array}{l}\text { "Sangat } \\
\text { Sehat" }\end{array}$ & 1 \\
\hline & Rata-Rata & 6.16 & 11.24 & 11.38 & 11.19 & 10.19 & 10.03 & $\begin{array}{l}\text { "Sangat } \\
\text { Sehat" }\end{array}$ & 1 \\
\hline
\end{tabular}

Sumber: Data diolah (2019)

\section{c. Beban Operasional, Pendapatan Operasional (BOPO)}

Berdasarkan Tabel 13 "menunjukkan bahwa rata-rata secara keseluruhan Beban Operasional dengan Pendapatan Operasional (BOPO) Bank Umum Syariah (BUS) yaitu $90.91 \%$ dengan predikat Kurang Sehat dengan nilai PK 4. BOPO tertinggi dimiliki oleh Bank Muamalat Indonesia dengan nilai rata-rata BOPO sebesar $97.67 \%$ dengan predikat Tidak Sehat dengan nilai PK 5 karena meningkatnya Beban Operasional Bank Muamalat Indonesia. BOPO terendah dimiliki oleh Bank BTPN Syariah dengan nilai BOPO sebesar $76.38 \%$ dengan predikat Sangat Sehat dengan nilai PK 1 karena rendahnya Beban Operasional yang dimiliki Bank BTPN Syariah".

Tabel 13 Kesehatan Bank Berdasarkan Rasio BOPO

\begin{tabular}{|c|c|c|c|c|c|c|c|c|c|}
\hline \multirow[t]{2}{*}{ No. } & \multirow{2}{*}{$\begin{array}{c}\text { Nama Bank Umum Syariah } \\
\text { Indonesia }\end{array}$} & \multicolumn{5}{|c|}{$\begin{array}{c}\text { Beban \& Pendapatan } \\
\text { Operasional }\end{array}$} & \multirow{2}{*}{$\begin{array}{l}\text { Rata- } \\
\text { Rata }\end{array}$} & \multirow[t]{2}{*}{ Predikat } & \multirow{2}{*}{$\begin{array}{l}\text { Perin } \\
\text { gkat }\end{array}$} \\
\hline & & 2014 & 2015 & 2016 & 2017 & 2018 & & & \\
\hline 1 & PT Bank Muamalat Indonesia & 97.33 & 97.36 & 97.76 & 97.68 & 398.24 & 97.67 & $\begin{array}{l}\text { "Tidak } \\
\text { Sehat" }\end{array}$ & 5 \\
\hline 2 & PT Bank Syariah Mandiri & 100.60 & 94.78 & 94.12 & 94.44 & 490.68 & 94.92 & "Sehat" & 4 \\
\hline 3 & PT Bank BTPN Syariah & 87.80 & 86.80 & 76.10 & 68.80 & 62.40 & 76.38 & $\begin{array}{l}\text { "Sangat } \\
\text { Sehat" }\end{array}$ & 1 \\
\hline 4 & PT Bank BRI Syariah & 99.77 & & 0132 & 20531 & 495.32 & 95.11 & $\begin{array}{l}\text { "Cukup } \\
\text { Sehat" }\end{array}$ & 3 \\
\hline 5 & PT Bank BCA Syariah & 92.90 & 92.50 & 92.20 & 87.20 & 87.40 & 90.44 & "Sangat & 1 \\
\hline
\end{tabular}




\begin{tabular}{|l|l|l|l|l|l|l|l|l|l|}
\hline & & & & & & & Sehat" & \\
\hline & RATA-RATA INDUSTRI & $\mathbf{9 5 . 6 8}$ & $\mathbf{9 3 . 0 5}$ & $\mathbf{9 0 . 3 0}$ & $\mathbf{8 8 . 6 9} 86.81$ & $\mathbf{9 0 . 9 1}$ & $\begin{array}{c}\text { "Kurang } \\
\text { Sehat" }\end{array}$ & $\mathbf{4}$ \\
\hline
\end{tabular}

Sumber: Data diolah (2019)

\section{Analisis Capital (Permodalan)}

Hasil analisis capital Bank Syariah Tabel 14 "menunjukkan bahwa rata-rata secara keseluruhan Capital Adequency Ratio (CAR) Bank Umum Syariah (BUS) yaitu 21.42\% dengan predikat Sangat Sehat dengan nilai PK 1 yang berarti seluruh Bank Umum Syariah (BUS) mampu untuk memenuhi KPMM terbukti dengan seluruh bank mendapat peringkat satu dengan predikat sangat sehat. CAR tertinggi dimiliki oleh Bank BCA Syariah dengan nilai rata-rata CAR sebesar $30.86 \%$ dengan predikat Sangat Sehat dengan nilai PK 1 karena meningkatnya kecukupan modal Bank BCA Syariah. CAR terendah dimiliki oleh Bank Muamalat Indonesia dengan nilai CAR sebesar $12.92 \%$ dengan predikat Sangat Sehat dengan nilai PK 1 karena rendahnya kecukupan modal yang dimiliki Bank Muamalat Indonesia".

Tabel 14 Kesehatan Bank Berdasarkan Rasio CAR

\begin{tabular}{|c|c|c|c|c|c|c|c|c|c|}
\hline \multirow{2}{*}{ No. } & \multirow{2}{*}{$\begin{array}{c}\text { Nama Bank Umum Syariah } \\
\text { Indonesia }\end{array}$} & \multicolumn{5}{|c|}{ Capital Adequency Ratio (CAR) } & \multirow{2}{*}{$\begin{array}{l}\text { Rata- } \\
\text { Rata } \\
\end{array}$} & \multirow{2}{*}{ Predikat } & \multirow{2}{*}{$\begin{array}{c}\text { Pering } \\
\text { kat }\end{array}$} \\
\hline & & 2014 & 2015 & 2016 & 2017 & 2018 & & & \\
\hline 1 & PT Bank Muamalat Indonesia & 13.91 & 12.00 & 12.74 & 13.62 & 12.34 & 12.92 & $\begin{array}{l}\text { "Sangat } \\
\text { Sehat" }\end{array}$ & 1 \\
\hline 2 & PT Bank Syariah Mandiri & 14.12 & 12.85 & 14.01 & 15.89 & $|16.26|$ & 14.63 & $\begin{array}{l}\text { "Sangat } \\
\text { Sehat" }\end{array}$ & 1 \\
\hline 3 & PT Bank BTPN Syariah & 32.80 & 19.90 & 23.80 & 28.90 & 40.90 & 29.26 & $\begin{array}{l}\text { "Sangat } \\
\text { Sehat" }\end{array}$ & 1 \\
\hline 4 & PT Bank BRI Syariah & 12.89 & 13.94 & 20.63 & 20.05 & 29.72 & 19.45 & $\begin{array}{l}\text { "Sangat } \\
\text { Sehat" }\end{array}$ & 1 \\
\hline 5 & PT Bank BCA Syariah & 29.60 & 34.30 & 36.70 & 29.40 & 24.30 & 30.86 & $\begin{array}{l}\text { "Sangat } \\
\text { Sehat" }\end{array}$ & 1 \\
\hline & RATA-RATA INDUSTRI & 20.66 & 18.60 & 21.58 & 21.57 & 24.70 & 21.42 & $\begin{array}{l}\text { "Sangat } \\
\text { Sehat" }\end{array}$ & 1 \\
\hline
\end{tabular}

Sumber: Data diolah (2019)

\section{Analisis Metode Risk Based Bank Rating (RBBR)}

Hasil Metode Risk Based Bank Rating (RBBR) Bank Syariah Tabel 15 m"enunjukkan bahwa rata-rata tingkat kesehatan Bank Umum Syariah (BUS) yang terdaftar di Otoritas Jasa Keuangan (OJK) dinilai dengan metode Risk Based Bank Rating (RBBR) tahun 2014-2018) di Indonesia yaitu nilai PK 2 dengan predikat Cukup Sehat. berdasarkan Pasal 2 Peraturan bank Indonesia No. 13/1/PBI/2011 dan sesuai yang telah dijelaskan dalam SE BI No. 13/24/DPNP 25 Oktober 2011, metode RBBR ini menitikberatkan pertimbangan kesehatan bank umum berdasarkan prinsip kehatihatian dan manajemen resiko".

Tabel 15 Kesehatan Bank Metode Risk Based Bank Rating (RBBR) Berdasarkan Industri Perbankan Syariah di Indonesia

\begin{tabular}{|c|c|c|c|c|c|c|c|c|c|}
\hline \multirow{2}{*}{ No. } & \multirow{2}{*}{ Pengukuran Keuangan } & \multicolumn{5}{|c|}{ Risk Based Bank Rating (RBBR } & \multirow{2}{*}{$\begin{array}{l}\text { Rata- } \\
\text { Rata }\end{array}$} & \multirow{2}{*}{ Predikat } & \multirow{2}{*}{ PK } \\
\hline & & 2014 & 2015 & 2016 & 2017 & 2018 & & & \\
\hline 1 & $\begin{array}{l}\text { Non Performing Loan } \\
\text { (NPL/NPF) }\end{array}$ & 3.58 & 3.87 & 2.82 & 3.03 & 2.52 & 3.17 & "Sehat" & 4 \\
\hline
\end{tabular}




\begin{tabular}{|c|l|c|c|c|c|c|c|c|c|}
\hline 2 & $\begin{array}{l}\text { Loan to Deposit Ratio } \\
\text { (LDR/FDR) }\end{array}$ & 89.03 & 88.89 & 87.71 & 82.99 & 82.10 & 86.14 & $\begin{array}{l}\text { "Cukup } \\
\text { Sehat" }\end{array}$ & 3 \\
\hline 3 & $\begin{array}{l}\text { Return On Asset (ROA) } \\
4\end{array}$ & 1.04 & 1.55 & 2.37 & 2.72 & 3.00 & 2.14 & $\begin{array}{c}\text { Sangat } \\
\text { Sehat" }\end{array}$ & 1 \\
\hline 5 & $\begin{array}{l}\text { Net Interest Margin (NIM) } \\
\text { Beban \& Pendapatan } \\
\text { Operasional (BOPO) }\end{array}$ & 6.16 & 11.24 & 11.38 & 11.19 & 10.19 & 10.03 & $\begin{array}{l}\text { Sangat } \\
\text { Sehat" }\end{array}$ & 1 \\
6 & $\begin{array}{l}\text { Capital Adequency Ratio } \\
\text { CAR) }\end{array}$ & 20.66 & 18.60 & 21.58 & 21.57 & 24.70 & 21.42 & $\begin{array}{l}\text { "Kurang } \\
\text { Sehat" } \\
\text { Sehat" }\end{array}$ & 4 \\
\hline \multicolumn{6}{|c|}{ KESEHATAN INDUSTRI } \\
\hline
\end{tabular}

Sumber: Data diolah (2019)

\section{E. KESIMPULAN}

\section{Kesimpulan}

Berdasarkan hasil analisis kesehatan BUS (Bank Umum Syariah) di Indonesia menggunakan "metode Risk Based Bank Rating (RBBR) menggunakan rasio NPL, LDR, ROA, NIM, BOPO dan CAR" sebagai berikut :

a Analisis Kesehatan "faktor risk profile atas resiko kredit dengan rasio rata-rata secara keseluruhan NPF dengan predikat Sehat. NPF tertinggi dimiliki oleh Bank Syariah Mandiri dengan predikat Cukup Sehat. NPF terendah dimiliki oleh Bank BCA Syariah dengan predikat Sangat Sehat. Risiko Likuiditas menunjukkan bahwa rata-rata secara keseluruhan Financing to Deposit Ratio (FDR/LDR) dengan predikat Cukup Sehat. FDR tertinggi dimiliki oleh Bank BTPN Syariah predikat Cukup Sehat. FDR terendah dimiliki oleh Bank Syariah Mandiri dengan predikat Sehat".

b. Analisis Kesehatan yaitu "faktor Earning (Rentabilitas) dengan ROA, NIM dan BOPO. Analisis rasio ROA terdapat rata- ratasecara keseluruhan Return On Asset (ROA) Bank Umum Syariah (BUS) yaitu predikat Sangat Sehat dengan nilai PK 1. ROA tertinggi dimiliki oleh Bank BTPN Syariah dengan predikat Sangat Sehat dengan nilai PK 1. ROA terendah dimiliki oleh Bank Muamalat Indonesia dengan predikat Kurang Sehat. Analisis rasio NIM rata- rata secara keseluruhan Net Interest Margin (NIM) dengan predikat Sangat Sehat dengan nilai PK 1. NIM tertinggi dimiliki oleh Bank BTPN Syariah dengan predikat Sangat Sehat nilai PK 1, NIM terendah dimiliki oleh Bank Muamalat Indonesia dengan predikat Sangat Sehat nilai PK 1. Analisis rasio BOPO rata-rata secara keseluruhan Beban Operasional dengan Pendapatan Operasional (BOPO) dengan predikat Kurang Sehat dengan nilai PK 4. BOPO tertinggi dimiliki oleh Bank Muamalat Indonesia dengan predikat Tidak Sehat dengan nilai PK 5, BOPO terendah dimiliki oleh Bank BTPN Syariah dengan predikat Sangat Sehat dengan nilai PK 1".

c. Analisis Kesehatan Bank "faktor Capital (Permodalan) diukur dengan rata-rata secara keseluruhan Capital Adequency Ratio (CAR) Bank Umum Syariah (BUS) dengan predikat Sangat Sehat dengan nilai PK 1. CAR tertinggi dimiliki oleh Bank BCA Syariah dengan predikat Sangat Sehat dengan nilai PK 1, CAR terendah dimiliki oleh Bank Muamalat Indonesia dengan predikat Sangat Sehat dengan nilai PK 1".

d Analisis Kesehatan Metode Risk Based Bank Rating (RBBR) menunjukkan "nilai PK 2.33 dengan predikat Cukup Sehat. berdasarkan Pasal 2 Peraturan bank Indonesia No. 13/1/PBI/2011 dan sesuai yang telah dijelaskan dalam SE BI No. 13/24/DPNP 25 Oktober 2011, metode RBBR ini menitikberatkan pertimbangan kesehatan bank umum berdasarkan prinsip kehatihatian dan manajemen resiko". 


\section{Saran}

Adapun saran yang dapat diberikan oleh peneliti atas penelitian yang telah dilakukan adalah sebagai berikut:

a Kondisi Risk Profile atas resiko kredit dengan rasio NPL dan resiko likuiditas dengan rasio LDR "untuk bank yang memperoleh predikat tidak sehat, kurang sehat dan cukup sehat sebaiknya bank harus berhati-hati dalam hal penyaluran kredit karena semakin besar kredit yang diberikan apabila tidak diimbangi dengan manajemen kredit yang baik akan berpotensi menimbulkan risiko kredit maupun risiko likuiditas yang dapat mengganggu kesehatan bank tersebut, dan yang sudah mendapat predikat sangat sehat atau sehat harus dipertahankan agar menjaga tingkat kesehatan bank".

b. Kondisi Earnings (Rentabilitas) "diukur dengan NIM dan ROA perlu dijaga dan dipertahankan serta ditingkatkan, sedangkan BOPO menunjukan Bank Muamalat Indonesia berpredikat tidak sehat, bank harus memperhatikan tingkat efisiensi biaya dan mengurangi resiko kredit dan likuiditas agar memperoleh keuntungan".

c. Kondisi Capital (Permodalan) bank "diukur menggunakan Capital Adequacy Ratio (CAR) mendapat predikat secara keseluruhan rata- rata sangat sehat, sebaiknya terus dipertahankan oleh manajemen bank agar kesehatan bank yang dinilai menggunakan metode Risk Based Bank Rating (RBBR) tetap terjaga".

d Penelitian ini hanya menganalisis tingkat kesehatan bank dengan metode Risk Based Bank Rating (RBBR) dengan tiga faktor, "yaitu faktor Risk Profile sesuai dengan ketentuan Bank Indonesia atas delapan resiko, namun pada penelitian ini menggunakan resiko kredit dan resiko likuiditas, faktor Earnings, dan faktor capital. Sehingga dalam menganalisis tingkat kesehatan bank peneliti belum mampu mengkompositkan tingkat kesehatan bank yang diwakili oleh empat faktor secara keseluruhan metode Risk Based Bank Rating (RBBR), dan diharapkan pada penelitian selanjutnya menggambarkan kesehatan bank yang sesuai Surat Edaran BI No 13/24/DPNP mengenai penilaian tingkat kesehatan bank metode Risk Based Bank Rating (RBBR)". 


\section{DAFTAR PUSTAKA}

A. Erika dan A. Astiti Chandra, "Penilaian Tingkat Kesehatan Bank: Pendekatan CAMEL dan RGEC (Studi Pada Bank Maybank Syariah Indonesia Periode 2011-2016)," Jurnal Akuntansi dan Keuangan Islam., vol. 6, no. 2, pp. 189-207, 2018.

Abdul Kadim, K., Nardi Sunardi, S., Hendro Waryanto, W., Dessy Adelin, A., \& Endang Kusmana, K. (2018). The Effects Of Bank Soundness With The RGEC Approach (Risk Profile, Good Corporate Governance, Earnings, Capital) Of Leverage And Its Implications On Company's Value Of State Bank In Indonesia For The Period Of 20122016. IJER (International Journal of Economic Research), 15(11), 41-52.

Bank Indonesia. (2012). Peraturan Bank Indonesia Nomor: 14/2/PBI/2012 tentang Perubahan atas PBI Nomor:11/11/PBI/2009 tentang Kegiatan Alat Pembayaran dengan Menggunakan Kartu.

H. Theresia Vania dan N. Nila Firdaus, "Analisis Tingkat Kesehatan Bank Berdasarkan Metode Risk Based Bank Rating (Studi Pada Bank Umum Konvensional Di Indonesia Periode 2014-2016)," Jurnal Administrasi Bisnis (JAB)., vol. 57, no. 1, 2018.

Jakarta: Otoritas Jasa Keuangan.

Jumingan. (2014). Analisis Laporan Keuangan.Jakarta :BumiAksara

Kasmir. (2013). Bank dan Lembaga Keuangan Lainnya. PT Raja Grafindo Persada

M. Siti Halimah, "Analisis Tingkat Kesehatan Bank Dengan Menggunakan Metode Risk Based Bank Rating (RBBR) Pada PT. Bank Rakyat Indonesia (Persero) Tbk," Jurnal Manajemen. 2019.

Munawir, S. (2012). Analisis Laporan Keuangan. EdisiKeempat. Yogyakarta: Liberty Otoritas Jasa Keuangan. (2016). Laporan Perkembangan Keuangan Syariah 2015.

Nardi Sunardi, E. A., Kadim, A., Tumanggor, M., \& Oktrima, B. (2018). Effects Of The Bank Soundness With The Rbbr Approach (Risk Base Bank Rating) Of Cost Efficiency And Its Implications On Sharia Bank Performance In Indonesia For The Period Of 20122016. International Journal of Economic Research, 15(1).

Otoritas Jasa Keuangan, (2015), Roadmap Perbankan Syariah Indonesia 2015-2019, Departemen Perbankan Syariah OJK, Jakarta.

P. Setyo dan D. Ari, "Analisis Kinerja Bank Umum Syariah Dengan Metode Risk Based Bank Rating (RBBR) Untuk Mengetahui Tingkat Kesehatan Bank (Studi pada Bank Umum Syariah yang Terdaftar di Otoritas Jasa Keuangan Republik Indonesia Periode 20142016)," Jurnal Administrasi Bisnis (JAB). vol. 56, no. 1, 2018.

Peraturan Perundang-undangan, (1992), Undang-undang Republik Indonesia Tahun 1992 Tentang Perbankan, DPR-RI, Jakarta 
Peraturan Perundang-undangan, 2008, Undang-undang Republik Indonesia Nomor 21 Tahun 2008 Tentang Perbankan Syariah, DPR-RI, Jakarta.

R. Sri dan E. Evi, "Analisis Tingkat Kesehatan Bank Umum Syariah Di Indonesia dengan Menggunakan Metode Risk-based Bank Rating tahun 2014-2016," Jurnal Al Amwal., vol. 9, no. 2, 2017.

S. Dea Amelia, A. Devi Farah, dan A. Zahroh Z, "Analisis Tingkat Kesehatan Bank Dengan Menggunakan Metode Risk Based Bank Rating (Studi Pada Bank Milik Pemerintah Pusat Yang Terdaftar Di Bursa Efek Indonesia Tahun 2012-2015)," Jurnal Administrasi Bisnis (JAB)., vol. 46, no. 1, 2017.

Sunardi, N. (2018). Analisis Economic Value Added (Eva), Financial Value Added (FVA) Dan Market Value Added (MVA) Dengan Time Series Approach Sebagai Alat Penilaian Kinerja Keuangan (Studi Pada Industri Konstruksi (BUMN) di Indonesia Yang Listing di BEI Tahun 2013-2017). Jurnal SEKURITAS (Saham, Ekonomi, Keuangan dan Investasi), 2(1).

Sunardi, N. (2018). Analisis Risk Based Bank Rating (RBBR) Untuk Mengukur Tingkat Kesehatan Bank Syariah Di Indonesia. JIMF (Jurnal IImiah Manajemen Forkamma), 1(2).

Sunardi, N., \& Oktaviani, L. (2016). Analisis Camel Dalam Menilai Tingkat Kesehatan Bank (Studi Kasus pada Subsektor Perbankan yang Terdaftar di BEl Periode 20112015). Jurnal IImiah IImu Manajemen.

W. Bobby, "Analisis Tingkat Kesehatan Bank Dengan Menggunakan Metode Risk-Based Bank Rating (RBBR) (Studi Pada Bank yang Termasuk Saham LQ45 Sub Sektor Perbankan Tahun 2010-2016)," Jurnal Akuntansi Maranatha., vol. 10, no. 1, 2018.

W. Rolia dan W. Khoiriyyah Rahma, "Metode RGEC: Penilaian Tingkat Kesehatan Bank Pada Perusahaan Perbankan Syariah," I-FINANCE., vol. 04, no. 02, 2018.

Y. Nora, S. Muhammad, dan A. Zahroh Z, "Analisis Tingkat Kesehatan Bank Dengan Metode RBBR (Risk-Based Bank Rating) (Studi pada Bank Umum Swasta Nasional Devisa yang Terdaftar di Bursa Efek Indonesia Periode 2012-2014)," Jurnal Administrasi Bisnis (JAB)., vol. 37, no. 1, 2016. 